\title{
A Review on Creating Drought Tolerant Crop Varieties
}

\author{
Ramesh Thatikunta \\ Acharya N. G. Ranga Agricultural University \\ College of Agriculture, Rajendranagar \\ India
}

\section{Introduction}

Sustainability and the overall management of water resources has been the one of the greatest challenges of the century. The world population has crossed the six billion mark. Based on the proportion of young people in the developing countries, the requirement for water would continue to increase significantly during the next few decades. This places enormous demand on the world's limited fresh water supply (Bharucha, 2005). United Nations estimates a total amount of water present on earth to be about $1400 \mathrm{M} \mathrm{km}^{3}$. Precipitation annually amounts to 1,10, $000 \mathrm{~km}^{3}$. Global current withdrawal amounts to $4500 \mathrm{~km}^{3}$, which exceeds the availability of approximately $4200 \mathrm{~km}^{3}$. By the year 2030, a global deficit of 40 per cent has been forecasted. At the same time, biotic and abiotic stresses which serve as barriers to achieve high crop yields tends to be on the increase. Such challenges can be met only by paying adequate attention to sustainable agriculture (Swaminathan and Jana,1992).

Available water resources for crop production include rainfall, canal water and ground water. Precipitation acts as a primary source of water for crops in command areas. Surface and ground water systems of irrigation supplement precipitation. Ground water through dug wells and bore wells supplement irrigation water requirement. Conjunctive use of surface and ground water can result in optimum utilization of water resources. Fresh water for agriculture around the world has become scarce, thereby threatens the productivity of crop lands. Causes for the increase in water scarcity have been diverse and location specific. These include falling ground water table, chemical pollution, malfunctioning of irrigation systems and increased competition from other sectors such as urban and industrial users. Farmers often experience total crop failure because of lack of water. Most of the rainfall received in rainfed areas show either erratic distribution or shortage at any particular stage of the crop leading to drought. To help the fate of water scarce farmers and to ensure global food security, every drop of water counts. Farmers do not invest enough in inputs to increase the crop production in such areas (Bouman and Aureus, 2009). Scarcity of irrigation water calls for well planned long term strategy for sustainable water resources management. Modernization of existing irrigation systems with better operation and maintenance involves participatory irrigation management (PIM), which could play an important role in irrigation management. PIM includes participation of users - the farmers - in planning, design, construction, operation, maintenance, financing, decision rules, monitoring and 
evaluation of irrigation system. For efficient use of limited irrigation water, precise knowledge of crop water requirements has become essential prerequisite (Reddy, 1999).

Water forms a major structural component and constitutes to 90 per cent of vegetative biomass. Only a small fraction is absorbed by plants and used in photosynthesis. As much as 99 per cent escapes as vapour by the process of transpiration. Accurate crop water requirement data has therefore become essential in irrigated agriculture. Methods of estimating crop water requirements depend on the desired level of accuracy, availability of equipment and technical know- how. The current review focuses on three objectives i.e., to explore the interactions and issues involved in extrapolating water use efficiency (WUE), second to outline the methods adopted to improve the efficiency in water use by soil and crop and third to spell out the success stories of effectiveness of water use.

\section{Historical perspective}

In rainfed areas, many traditional cultivars tolerant to drought have evolved because of continuous farmer selection pressure in drought environments over time. Besides, there also exists, a wide variety of indigenous plants that thrive with minimal or no irrigation, fertilizer or pest control. Ideally these native land races that thrive on natural rainfall do best in an ecosystem. There are many native Hawaiian plants that are less thirsty.

Farmers in their fields, mainly have to deal with technologies that reduce the non productive outflows (percolation, seepage and evaporation) while transpirational flows are maintained by plants. This can be practiced during land preparation, and during the actual crop growth period. Sandy soil drains well. The loose structure makes it easy to dig, warm up quickly after the winter months, aiding plant growth. At the same time less organic matter and minimum ability to retain water, offers plants less water and nutrients needed for healthy growth. The addition of compost greatly enhances the ability of sandy soil to retain enough water. Mulch placed on top of the beds helps to reduce the water loss. Such soil based inputs form the basis to improve crop productivity. Realizing the importance of soil and water conservation, farmers used to protect their lands especially rainfed by construction of long lines of bunds made of stones and or earth. Small tanks were construnted to retain and store rain water. Soil erosion control studies were initiated by German soil scientist Wollny between 1877 and 1895. Ten research centres were established in USA during the period from 1928 to 1933. A major stimulus for water requirement studies have been from the development of irrigation facilities in the western United States in the middle of nineteenth century and which expanded during the later part of that century (Jensen, 1968).

In the last century the increase in yield was mainly due to three reasons. First of this rise was due to better nutrition. Second was due to the introduction of highly productive pasture legumes which provided rich source of nitrogen to the following crops. Third and most spectacular was the control of endemic root diseases which gave farmers the confidence to apply more nitrogen which resulted in large responses in yield (Passioura, 2004).

\section{Reduction in evapotranspiration}

Attempt to control the supply of water to crops must be based on the understanding of variable state of water in the soil and its cyclic movement into, within and out of root zone. 
The cycle of water in the field and its uptake by plants has been governed by evaporation (E), transpiration (T) which are collectively known as evapotranspiration (ET) and ET along with metabolic needs of the plant has been referred to as consumptive use (CU). Evaporation referred to as a cooling process includes latent heat of vapourization (585 $\mathrm{cal} \mathrm{g}^{-1}$ of evaporated water). Transpiration on the other hand, leaves the body of a living plant and reaches the atmosphere as water vapour. However, a major difference exists between transpiration and evaporation. Transpiration essentially confines itself to day light hours and the rate depends on growth periods of plants. Evaporation, on the other hand continues all through the day and night with different rates. Factors that play an important role in evapotranspiration include physical (vapour pressure deficit, wind speed, quality of water), plant (rooting characteristics, distribution of stomata, roughness of leaf) and soil factors (available soil moisture, exposed soil surface). Potential yields are realized upon adequate supply of water through out the crop growing season and when ET is expected to be at its maximum. An ideal irrigation schedule for optimum yield indicates the correct timing (when to irrigate). Other factors of importance are soil and topography. In poorly permeable soils, percolation losses will be low and surface losses relatively high. In very permeable soils, percolation losses will be high and surface losses relatively low. With increase in slope, the risk of excessive infiltration losses become less, but the surface losses increase. Run off from the soil surface may be substantial during heavy rain, but much of the rain becomes run on in lower parts of the field. The net result is a little net loss from the field as a whole as there occurs greater vertical drainage from the low lying areas.

In principle the rate of water uptake by plants depends on the ability of roots to absorb water from soil with which they are in contact, as well as on the ability of soil to supply and transmit water towards roots at a rate sufficient to meet transpiration and growth requirements. These variables in turn depend on plant, soil and weather conditions. Cooper et al, (1983) gave a technique to calculate seasonal evaporation which ranged from about 60$160 \mathrm{~mm}$.

Loss of water varies with seasonal weather and as well with the rate of development of leaf canopy and the presence of leaf mulches such as from stubbles of the previous crop. Impact of canopy size on evaporative loss from the soil can be manipulated by varying the crops nitrogen supply. Overall WUE values were not necessarily higher at luxurious nitrogen supply and ranged from 11-20 kg ha-1 $\mathrm{mm}^{-1}$, as the crop could use too much of water during its vegetative stage and run out of water during grain filling period.

Evaporative losses of water from soil surface, can be minimized by the crop if there exists a rapid early development of leaf area which enhances the productive flow of water through the plants. Plant coverage of soil can also improve the carbon dioxide uptake. However trade off of too much water use during vegetative growth may leave little for grain filling.

The method of irrigation also contributes to irrigation losses. Application of the least amount of water required to bring the root zone depth to field capacity has been considered as efficient irrigation. The major control of irrigation rests in the hands of irrigator in the field. Quality of irrigation water assumes importance in arid climates where high rates of evaporation contribute to increased salt concentration in soil and drainage water. Application of saline or brackish water may hinder crop growth directly and also cause soil degradation. In a season application of $1000 \mathrm{~mm}$ of medium quality water introduces five 
tones of salt to one hectare. In all such instances proper leaching and drainage become an integral part of farming (Reddy, 1999).

Water plays a central role in the metabolism of plants. Loss of water from plant canopies by transpiration sets up a chain of reactions to replace the water lost. To design a successful irrigation system it becomes imperative to know the plant rooting characteristics, moisture extraction pattern and moisture sensitive stages.

Root systems in the field are seldom uniform with depth. Rooting depth of annual field crops on deep well drained soils range from 0.30 to $2.0 \mathrm{~m}$. In general, root zone depth of crops reduces by 25 to 35 per cent on clayey soils and increased by 25-35 per cent on sandy soils. Usual moisture extraction shows that, about 40 per cent of the extracted moisture comes from upper quarter of the root zone while, 30, 20 and 10 per cent from lower quarters. Low frequency irrigation leads to depleting soil moisture from lower quarter of the root zone depth. Based on rooting depth field crops have been classified into shallow (rice, onion, cabbage, cauliflower, potatoes), medium (barley, wheat, castor, tobacco, chillies, peas, tomato) and deep rooted (cotton, maize, sorghum, pearl millet, sugarcane, soybean).

Optimum soil moisture for plant growth varies with the stage of crop growth. Certain periods of crop growth and development are more sensitive to soil moisture stress compared with others (panicle initiation, heading, flowering for rice, heading and flowering for pearl millet, flowering, seed formation for soybean and commencement of fruit set for tomato). Inadequate water supply during sensitive periods will irrevocably reduce the yield. Provision of adequate water and along with other management practices or at other growth stages would not help in recovering of the lost yield.

Lack of rainfall either through insufficient irrigation or rainfall causes drought stress in plants wherein too little water is available in a suitable thermodynamic state (Larcher, 2003). Rice crop needs twice as much of water, than many other crops to produce good yields. For production of one $\mathrm{kg}$ of rough rice 2500 liters of water is needed, of which, 1400 liters are used up in evapotranspiration and 1100 liters are lost in seepage and deep percolation (Bouman and Aureus, 2009). To grow crops like rice with special water requirements, lack of water at one critical plant growth stage or another can decrease productivity. Besides, erratic distribution and shortage particularly at flowering and again at grain filling seriously limits productivity depending on the growing duration of the crops or varieties. Such of those losses need to be quantified in various crops and efforts made to reduce them without any decrease in the yield. These aspects need to be justified in crops and situations.

\section{Available technologies}

Annual rainfall in several parts of drylands may be sufficient to raise one or two crops. In such areas high intensity storms and erratic rainfall leads to runoff and erosion. The effective rainfall is less than 50 per cent and seldom exceeds and reaches 65 per cent. In all such instances soil management practices need to be tailored to store and conserve as much rainfall as possible by reducing runoff and increasing storage capacity of soil profile. A number of simple technologies (tillage, fallowing, mulching, contour bunding) have been developed to prevent or reduce water losses and to increase water intake.

Farmers who practice alternate wetting and drying (AWD) method, use the field tube technology to monitor the underground water. When the water level fell below $15-20 \mathrm{~cm}$ 
below the surface of the soil, field was again flooded. The technology reduced the amount of water by a quarter and more importantly it did not reduce the crop yields (Bouman and Aureus, 2009).

Over the seasons water escapes the roots of annual crops and accumulates in deep sub soil and becomes accessible to the roots of deep rooted perennial agricultural crops like Lucerne grown for two to three years. Such crops prove valuable when they are sown at the start of the drought. Lucerne also reduces the risk of environmental damage such as dry land salinity and eutrophication of discharge areas (Ridley et al., 2001).

Semi dwarf varieties dominate wheat cultivation throughout the world. The dwarfism in these arises from insensitivity to gibberellic acid (GA) conferred by genes Rht 1 and Rht2 which exhibit short coleoptiles. Seed sown deeply i.e., $>60 \mathrm{~cm}$ dies as the leaf does not emerge from soil. Here agronomy and breeding strongly affect crop canopy development. The aspect assumes importance when the seed is directly sown on untilled soil in dry lands where soil structural problems arise. Rht 8 a candidate gene enables emergence from sowing depths as great as $120 \mathrm{~mm}$ but yet provides adequate dwarfing of the canopy (Rebetzke $e t$ al., 1999).

Intensified efforts of International Rice Research Institute (IRRI) to cope with this looming water shortage, has lead to development of drought tolerant cultivars that use less water (aerobic rice). Reduction in length of growing period by two weeks, ahead of the previously used varieties of shorter duration allowed crop to be harvested, three times instead of two times a year. Such varieties can be planted even in dry season without any fear of loss. Once again, with the onset of rain the same crop which showed wilting has recovered. Thus it has been revealed that the crop could experience drought at any stage and withstand drought even at the reproductive stage, when crop suffers the maximum. The drought tolerance trait enables broadcasting of seeds in lieu of transplanting whereby saving a lot of money on labourers to plant the seedlings. The success of adoption of the variety was more attributed to farmer to farmer influence and support from the local government. Farmers were also pleased with plant traits like its ability to tolerate a month long drought, recovery from stress, early maturity and good eating quality.

The "stay green" character in case of sorghum arises from the positive feed back in nitrogen acquisition. Plants in this case maintain nitrogen in their leaves during grain filling and fix more carbon, which in turn enables roots to continue extracting soil nitrogen, so that the system is self reinforcing (Borrell et al., 2001). "Haying off" in which the crop senesces prematurely and its yield responds negatively to nitrogen can result from the phenomenon that when ever plant takes up nitrogen from either fertilizer or mineralization of organic matter, grows vigourously, utilizes too much of water before flowering, sets large number of flowers for which the plant can not mobilize carbohydrates from current photosynthesis or from remobilized sources and results in low yields.

Several earlier studies reported low selection efficiency for grain yield under drought stress. Much of the initial efforts focused on improvements of secondary traits such as root architecture, leaf water potential, panicle water potential, osmotic adjustment and relative water content. Recent studies have proved that these traits rarely have higher broad sense heritability $(\mathrm{H})$ than grain yield under drought stress and are often not highly correlated with grain yield (Kumar et al., 2008). 
Plant breeders have produced a large number of cultivars that flower close to optimal time in a given environment. Global warming in the coming decades could alter the time of flowering. Breeders are now in a position to tune the phenology even without being consciously aware that they are doing so.

In the face of the troubling reality, to help farmers to cope with the water scarce situations several approaches / technologies have been developed across the globe. Concerted efforts are needed through an interdisciplinary approach, to define criteria for stress assessment and to evolve breeding approaches for incorporating stress tolerance in crops (Paroda, 1986). Some of these methodologies include those of IRRI which works with national agricultural and extension system (NARES) for the evaluation of newly developed breeding lines, India - IRRI collaborative project and drought breeding network (DBN) that identifies the promising entries for drought prone ecosystem. Participatory varietal selection (PVS) testing and evaluation aims to develop prototype aerobic rice production systems for water scarce environments. Variety identification committee (VIC) recommends release of varieties to the central sub committee on crop standards Notification and Release of Varieties (Reyes, 2009).

In the recent times new concepts were initiated and experiments were conducted on direct selection for grain yield under drought stress wherein high yield potential under irrigated situation was combined with good yield under drought. Drought Physiologist involved in dissecting the mechanisms of drought tolerance and its genetic variation in rice, says that combining high yield potential and drought tolerance through direct selection for grain yield is one of the right approaches for developing drought-tolerant lines. In addition, new molecular tools like marker-assisted selection can aid in crop improvement. Previously scientists who worked on to improve the traits thought that drought tolerance was related to traits like leaf rolling, rooting depth etc. They believed that yield under drought could be increased by improving these secondary traits. Their efforts resulted in limited success. In this context, it is noteworthy to state that a successful recurrent selection for increased grain yield in drought stressed tropical maize was associated with a decrease in root mass (Bolanos et al., 1993).

\section{Success stories}

Biotic and abiotic stresses which become a part of climate change show uncertainties that can be met only by paying adequate attention to the biological software essential for sustainable agriculture. Identification of plant attributes that are important for such farming conditions forms an efficient plant breeding strategy. On the other hand conservation of genetic diversity under the conditions that promote desirable combinations of plant attributes in individual genotypes and enhance their frequency acts as an effective strategy to reduce genetic vulnerability (Swaminathan and Jana, 1992).

Conventional breeding for drought tolerance revolved around to develop populations with large genetic variation by phenotyping populations. Extensive efforts made in the last ten years to tackle the most complex and recalcitrant abiotic stress i.e., drought, improved rice yields in rainfed drought prone ecosystems. Direct selection for grain yield assessed under low land reproductive stage stress involved crosses between tolerant parents and lines with high yield potential, followed by direct selection of progeny in replicated trials for yield 
under optimal conditions and managed stress. In all such instances creation of stress levels that reduce the yield by 65 to $85 \%$ relative to unstressed controls only proved worthwhile. Stress was created by use of reliable tensiometers in trails, by use of number of drought susceptible and tolerant checks at repeated intervals, monitoring leaf rolling and leaf drying, proper monitoring of water table depth in low land trials. Irrigation by over head sprinklers were used in evaluation of upland stress. These served as tools that can assist breeders in selection. Three genotypes viz., IR 42253-61-1-1-2-3, JGL 384 and Badshah Bhog significantly out yielded the two mega varieties IR64 and Swarna. Yield advantage in stress selected lines was mainly due to high harvest index (HI) under stress (Kumar et al., 2008). IRRI has come out with two drought tolerant rice breeding lines and recommended their release. IR7437170-1-1 (Sahbhagi dhan) in India and its sister line IR74371-54-1-1 (5411) in the Philippines showed wide adaptability and have major impacts on the life and sustainability of farmers (Reyes, 2009).

Stable isotopes of carbon and oxygen have been used extensively as an interdisciplinary approach to save and utilize the available water by crops. The work on stable isotopes has led to breeding programme that involved carbon isotope discrimination (CID). The isotopic analysis of plant tissues enabled selection for intrinsically transpiration efficient plants. The technique resulted in production of wheat cultivar "Drysdale" now in commercial use in Australia. This is one of the very few examples of physiological analysis leading directly to a new cultivar. The variety has a promise to increase water limited yields by ten percent above the widely grown cultivar - Hartog. The breeding line was selected for intrinsically higher transpiration efficiency. As expected the trait has greater impact when the rainfall has been low (Passioura, 2004).

\section{Novel approaches}

Revolutionary changes in cropping patterns are expected when availability of irrigation water extends to five to six months in a year. Farmers can take up one or more additional crops after the harvest of main crop in the same land. Allotment of 33 and 67 per cent of area for wet cultivation in kharif in black soils and ill drained and water logged areas appears to be the ideal pattern for localization. Where ever single distributory or pipe outlet was available, pattern of irrigation to be followed would be wet or light irrigation with cultivation of less water intensive high value crops. The criteria for selection of main and second crops would be that main crop has to be grown in wet or monsoon season and second crop to be grown in dry season. For multiple cropping to be successful, a combination of fine and dry weather with sufficient irrigation and adequate drainage becomes essential.

The traditional methods (like diallel analysis, generation mean analysis, factorial design etc.) were used to investigate the genetic control of quantitative traits. These techniques however, do not provide information on the chromosome regions governing the naturally occurring variability in WUE and on the genetic causes like linkage or pleiotropy and their association with yield. Roots were observed to be positively associated with yield under drought stress and the region RG939-RG214 on chromosome 4 strongly affected root traits and yield. It is notable that successful recurrent selection for increased grain yield in drought stressed maize was associated with decrease in root mass. Whereas in crops which have limited capacity to adjust osmotically, water use and yield stabilization under drought with stored 
moisture available in deeper soil layers was recovered in genotypes with selection for faster growing and deeper roots (Bolonos et al., 1993). The difficulty in studying roots was circumvented by growing plants in pots and / or chambers filled with soil as is the case with rice (Wade et al., 2000).

There has been a considerable debate in recent years on the potential impact of biotechnologies in agriculture. The impact of biotechnology in overcoming hunger may have to wait till the next millennium. The tools of biotechnology can help raising the productivity of major crops through an increase in total dry matter production which can then be partitioned in a way favourable to the economic part. Enhancing biomass production and its conversion into energy have important applications like as in cardamom, oil palm through tissue culture methodologies (Swaminathan, 1992).

For improving crop performance in terms of WUE and other traits associated with yield through marker assisted selection (MAS), it has become essential to map the quantitative trait loci (QTLs). The next logical step is to identify suitable candidate genes accounting for QTL effects, validate their roles and proceed with manipulation with the gene itself. Identification of genes and elucidation of their role can be facilitated through high throughput profiling of "omics" approach which includes transcriptomics, proteomics and metabolomics. These new approaches provide opportunities and challenges to analyze the changes in concerted expression of thousands of genes to evaluate the responses to water deficit (Tuberosa, 2004). Some of the constraints can be partially overcome through the identification of QTLs. The dissection of quantitative trait has been possible through the production of experimental population consisting of either 100-200 $\mathrm{F}_{2}$ plants, $\mathrm{F}_{3}$ families, recombinant inbred lines (RIL), double haploids derived from a cross between two inbred lines differing for a trait of interest. Molecular distance of about $20 \mathrm{cM}$ becomes essential to detect the presence of QTL having a major effect on the phenotype. Model species like arabidopsis need 40-50 markers and over 300 needed in large genome species like durum and bread wheat to detect QTLs. Logarithm of odds ratio (LOD) ( $\log _{10}$ of the ratio between the chance of a real QTL measured at a position divided by the chance of having similar effect with no QTL present can be set to a score of $>2.5$ in the mapping population under study. Such detection also avoids false positive QTLs (i.e., declaring the presence of a ghost QTL when the actual QTL is absent). The technique of QTL analysis also enables with precision the genetic basis of trait association merely by looking for co location of the genetic map of the corresponding QTL and comparing the effect of the trait. The differing mapping populations profiled with a set of restriction fragment length polymorphism (RFLP) and simple sequence repeat (SSR) markers has made it possible for detailed comparison between the QTLs. For example in rice, the mapping populations most extensively used for root traits and other WUE traits has been derived from Bala x Azucena (Price and Tomos, 1997). It becomes orthwhile to mention here that QTLs for flowering time has already been cloned in rice (Kojima et al., 2002) and the positional cloning of $V g t 1$ is well advanced in wheat (Salvvi et al., 2002).

Now through molecular approaches, major QTLs for grain yield under drought have been identified in the background of popular mega varieties. The aim is to pyramid these QTLs and enhance the yield. Physiological and molecular mechanisms like Marker Assisted Selection (MAS) related to drought tolerance in some of the QTLs have been studied in rice and other crops as well and varieties have been in pipeline for release. From the information 
reviewed it becomes evident that genetic variability in WUE is an interaction of multitude of quantitatively inherited morpho-physiological traits whose effect on yield varies considerably according to the prevailing environment. Undermining such traits and understanding their cause effect relationships simplifies the complexity of a trait and makes it amenable for direct selection by a breeder (Tuberosa, 2004).

\section{Summary}

There has been an increase in the demand for more food from the natural resources to feed the growing population. At the same time, the primary concern has been to improve the efficiency of soil and plant water use to bring about productivity. Among the traits more attention needs to be paid to improve intrinsic and / or seasonal WUE, root architecture and photosynthetic efficiency.

In the past both empirical and analytical breeding have contributed to the improvement of seasonal WUE and yield of crops under both well watered and water limited conditions. This has been possible not only due to better partitioning but also due to increased biomass production. The latter has been possible by increased extraction of water from soil rather than by increased intrinsic WUE. Dyrsdale has been an exception as its yield advantage and selection is based on $\Delta{ }^{13} \mathrm{C}$ studies.

New initiatives integrating population biology with socio economics are required for sustainable management and utilization of worlds rapidly diminishing biological wealth. It must be realized that past approaches to achieving quick fix genetic advance are no longer appropriate. Interdisciplinary coordinated nature of work is needed and has resulted in development of less thirsty varieties, though, much hope depends on use of conventional breeding techniques with the available new technologies that include use of markers to bring about sustainability.

The challenge would be to best and most effectively integrate the materials developed by conventional breeding and the information generated through the new innovative techniques and approaches.

\section{References}

Bharucha Erach. 2005. Text book of environmental studies for undergraduate courses. University press, New Delhi, pp 13-49.

Bolanos, J., Edmeades, G and Martinez, L. 1993. Eight cycles of selections for drought tolerance in lowland tropical maize. III. Response in drought adaptive physiological and morphological traits. Field Crops Research, 31: 269-286.

Borrell, A., Hammer G and Van Oosterom, E. 2001. 2001. Stay green: A consequence of balance between supply and demand for nitrogen during grain filling? Annals of Applied Biology, 138: 91-95.

Bouman, B and Aureus, A. 2009. Every drop counts. Rice Today. IRRI Publishers, pp 16-18.

Cooper, P. J. M., Keatinge, J. D. H and Hughes, G. 1983. Crop evapotranspiration - a technique for calculation of its components by field measurements. Field Crops Research, 7: 299-312. 
Jensen, M. E. 1968. Water consumption by agricultural plants. In: (Kozlowski, T. T. Ed.). Water deficit and plant growth, Volume II. Plant water consumption and response. Academic Press. New York. 1-22.

Kojima, S., Takahashi, Y., Kobayashi, Y., Monna, L., Saski, T., Araki, T and Yano, M. 2002. $H d 3 a$, a rice orthologue of the Arabidopsis FT gene promotes transition to flowering downstream of Hd1 under short day conditions. Plant and Cell Physiology, 43: 1096-1105.

Kumar, A., Jerome Bernier., Satish Verulkar., Lafitte, H. R. and Atlin, G.N. 2008. Breeding for drought tolerance: Direct selection for yield, response to selection and use of drought tolerant donors in upland and low land - adapted populations. Field Crops Research, 107: 221-231.

Larcher Walter. 2003. Physiological plant ecology. (Larcher Walter. Ed.). Ecophysiology and stress physiology of functional groups. Springer. 401-416.

Paroda, R. S.1986. Breeding approaches for drought resistance in crop plants. In: (Chopra, V. L. and Paroda, R. S. Ed.). Approaches for incorporating drought and salinity resistance in crop plants. Oxford and IBH Publishing Co Pvt. Ltd. New Delhi. 87107.

Passioura John. 2004. Water use efficiency in farmers fields. In: (Mark A Bacon. Ed.) Water use efficiency in plant biology. Blackwell Pub. CRC press. U. K. 302-318.

Price, A. H and Tomos, A. D.1997. Genetic dissection of root growth in rice (Oryza sativa L.) II. Mapping quantitative trait loci using molecular markers. Theoretical and Applied Genetics, 95: 143-152.

Rebetzke, G. J., Richards, R. A., Fischer, V. M and Mickelson, B. J. 1999. Breeding long coleoptiles, reduced height wheats. Euphytica, 106, 159-168

Reddy S, R. 1999. Irrigation water management. In Principles of Agronomy (Reddy S.R. Ed.), Kalyani publishers. New Delhi. 346-520.

Reyes, C Lanle. 2009. Making rice less thirsty. Rice Today, 12-15.

Ridley, A, M., Christy, B., Dunin, F. X., Haines, P. J., Wilson, K. F and Ellington, A. 2001. Lucerne in crop rotations on the reverine plains 1 . The soil water balance. Australian Journal of Agricultural Research, 52: 263-277.

Salvi, S., Tuberosa, R., Chiapparino, E., Maccarerri, M., Veillet, S., Van Beuningen, L., Issac, P., Edwards, K and Phillips, R, L. 2002. Towards positional cloning of Vgt1, a QTL controlling the transition from the vegetative the reproductive phase in maize. Plant Molecular Biology, 48: 601-613.

Swaminathan, M. S. 1992. Biodiversity and biotechnology : Biodiversity implications for global food security (Swaminathan, M, S. and Jana, S. Ed.) . Macmillan India limited, Madras. 264-277.

Swaminathan, M. S. and S Jana. 1992. Introduction In : Biodiversity implications for global food security (Swaminathan, M, S. and Jana, S. Ed.). Macmillan India ltd. Madras. 1-7.

Tuberosa, R. 2004. Molecular approaches to unravel the genetic basis of water use efficiency. In : (Mark A Bacon. Ed.). Water use efficiency in plant biology. Blackwell publishers. CRC press. U. K. 228-282.

Wade, L. J., Kamoshita, A., Yamauchi, A. and Azhiri-Sigari, T. 2000. Genotypic variation in response of rainfed low land rice to drought and rewatering. I. Growth and water use. Plant Production Science, 3, 173-179. 


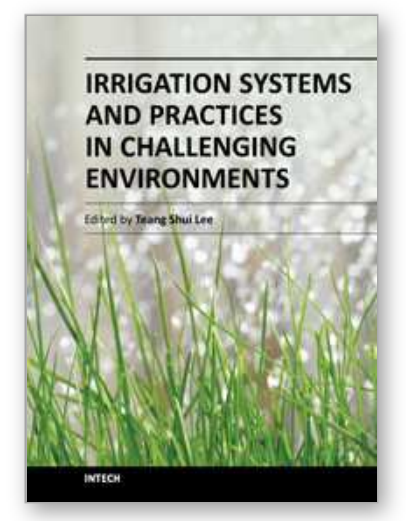

\author{
Irrigation Systems and Practices in Challenging Environments \\ Edited by Dr. Teang Shui Lee
}

ISBN 978-953-51-0420-9

Hard cover, 370 pages

Publisher InTech

Published online 28, March, 2012

Published in print edition March, 2012

The book Irrigation Systems and Practices in Challenging Environments is divided into two interesting sections, with the first section titled Agricultural Water Productivity in Stressed Environments, which consists of nine chapters technically crafted by experts in their own right in their fields of expertise. Topics range from effects of irrigation on the physiology of plants, deficit irrigation practices and the genetic manipulation, to creating drought tolerant variety and a host of interesting topics to cater for the those interested in the plant water soil atmosphere relationships and agronomic practices relevant in many challenging environments, more so with the onslaught of global warming, climate change and the accompanying agro-meteorological impacts. The second section, with eight chapters, deals with systems of irrigation practices around the world, covering different climate zones apart from showing casing practices for sustainable irrigation practices and more efficient ways of conveying irrigation waters - the life blood of agriculture, undoubtedly the most important sector in the world.

\title{
How to reference
}

In order to correctly reference this scholarly work, feel free to copy and paste the following:

Ramesh Thatikunta (2012). A Review on Creating Drought Tolerant Crop Varieties, Irrigation Systems and Practices in Challenging Environments, Dr. Teang Shui Lee (Ed.), ISBN: 978-953-51-0420-9, InTech, Available from: http://www.intechopen.com/books/irrigation-systems-and-practices-in-challenging-environments/areview-on-creating-drought-tolerant-crop-varieties

\section{INTECH}

open science | open minds

\section{InTech Europe}

University Campus STeP Ri

Slavka Krautzeka 83/A

51000 Rijeka, Croatia

Phone: +385 (51) 770447

Fax: +385 (51) 686166

www.intechopen.com

\section{InTech China}

Unit 405, Office Block, Hotel Equatorial Shanghai

No.65, Yan An Road (West), Shanghai, 200040, China

中国上海市延安西路65号上海国际贵都大饭店办公楼 405 单元

Phone: +86-21-62489820

Fax: $+86-21-62489821$ 
(C) 2012 The Author(s). Licensee IntechOpen. This is an open access article distributed under the terms of the Creative Commons Attribution 3.0 License, which permits unrestricted use, distribution, and reproduction in any medium, provided the original work is properly cited. 